\title{
Perspectivismo y crítica social. De Nietzsche a la Teoría Crítica
}

\section{Perspectivism and Social Critique. From Nietzsche To Critical Theory}

\author{
José Manuel Romero Cuevas \\ (Universidad de Alcalá de Henares)
}

Recibido: 14/03/13

Aceptado: 12/11/2014

\section{Resumen}

El presente artículo se confronta con una problemática que ha focalizado los debates teóricos en torno a los fundamentos normativos de la crítica en las últimas décadas. La cuestión es si, en un marco social escindido como el nuestro, la crítica tiene que asumir su carácter perspectivista, es decir, su estar ubicada en una de las perspectivas que se enfrentan en el escenario social. Si ello es así, el problema que se abre es el de la posibilidad o no de legitimar racional, moral y políticamente una crítica que asume su estar ya siempre situada en uno de los horizontes normativos que coexisten en el marco social. Este trabajo afronta este problema poniendo en diálogo motivos de la hermenéutica y de la teoría crítica: con ello pretende realizar una aportación a lo que podríamos llamar una reflexión hermenéutica de la crítica, que logre articular carácter perspectivo y pretensión de normatividad de la misma.

Palabras clave: crítica, teoría crítica, hermenéutica, perspectivismo, Nietzsche, Heidegger, Gadamer.

\begin{abstract}
This article tackles a problem that focused the theoretical debate about the normative basis of critique in the last decades. My question is if the critique, in a divided social frame as ours, must assume its perspectivistic character, that is to say, its location in one of the perspectives in confrontation within social reality. The problem arises if it is possible to authenticate a critique that assumes its situation inside one of the normative horizons that coexist in society, in a rational, moral and polit-
\end{abstract}


ical sense. This article discusses the problem by putting into dialogue motives from Hermeneutics and Critical Theory: This is how the author pretends to contribute to a hermeneutical reflection about critique that achieves joining together perspectivism and normativeness.

Keywords: Critique, Critical Theory, Hermeneutics, Perspectivism, Nietzsche, Heidegger, Gadamer.

\section{Niveles y alcance del perspectivismo en $F$. Nietzsche}

El perspectivismo hace referencia en la obra de Nietzsche a la vinculación constitutiva de la experiencia a una determinada apertura al mundo, lo cual implica su carácter necesariamente valorativo e interesado y la imposibilidad de un acceso objetivo, neutral, a la realidad. En su obra, la base para el perspectivismo se articula en diversos niveles. En primer lugar, la especie humana, en cuanto resultado de la evolución biológica y en cuanto compartiendo un bagaje biológico común, constituye la base de una primera y básica forma de perspectivismo. Las ciencias naturales, por ejemplo, estarían ligadas a la perspectiva de la especie humana respecto a la naturaleza y en las mismas no se plasmaría por tanto un acceso objetivo y neutral a lo real sino el cúmulo de intereses, necesidades y condiciones de supervivencia del ser humano en cuanto especie. El perspectivismo tendría como sustento en Nietzsche también las diferencias entre los distintos tipos humanos. Esta distinción, efectuada en un plano fisiológico-espiritual (que en Nietzsche constituye una dimensión indiferenciable), se realizaría fundamentalmente entre tipos inferiores, resentidos respecto a la vida, y los superiores, afirmadores de la inmanencia. Naturalmente, en el plano individual habría lugar para un perspectivismo específico, aunque Nietzsche tendió a considerar a los individuos concretos en cuanto miembros de uno u otro tipo humano. Finalmente habría también un perspectivismo definido por la pluralidad intrínseca a los propios individuos, es decir, un perspectivismo ligado a cada uno de los instintos, impulsos y fuerzas que integran esa realidad internamente antagónica que es el cuerpo individual. De esta forma, cada instinto, impulso y fuerza del individuo definiría su propia perspectiva, en pugna con las demás, sobre el mundo ${ }^{1}$.

En cada uno de estos planos, lo determinante es la idea de que toda apertura al mundo, toda experiencia de la realidad, está ligada a una perspectiva específica, lo cual implica que serían las condiciones de subsistencia, reproducción y aumento de

\footnotetext{
1 Desarrollo los diversos niveles de significado del concepto de perspectivismo de Nietzsche en $E l$ caos y las formas. Experiencia, conocimiento y verdad en F. Nietzsche, Granada, Comares, 2001, pp. 130-140.
} 
la potencia de tal perspectiva, sus intereses y necesidades propias, las que definen los parámetros que posibilitan su particular experiencia del mundo. El perspectivismo nietzscheano supone así la ruptura con toda concepción de la ciencia y del conocimiento como desligados de la esfera de la praxis y de los intereses humanos, como aproximación neutral, objetiva, a la realidad y con el concepto de sujeto de conocimiento que le corresponde. Según el perspectivismo, el sujeto de conocimiento es impuro y el intento de depurarlo de todo interés y facticidad sólo conduce a una ficción teórica que abre la puerta a la irrupción incontrolada de intereses espurios y encubiertos. En concordancia con esto, se problematiza además la concepción de la realidad del cientificismo positivista, que supone un mundo compuesto de hechos ya estructurados independientemente de toda teoría, a los que el científico puede acceder como mero observador desinteresado: "Contra el positivismo, el cual insiste en mantener frente a los fenómenos «sólo hay hechos», yo diría: no, precisamente no hay hechos, sólo interpretaciones"2.

Cuando Nietzsche, en sus últimos escritos, sobre todo en el Nachlass, afronta el problema del conocimiento en el ámbito de la relación entre ser humano y mundo, extrae de la vinculación de toda forma de experiencia de la realidad a una determinada perspectiva y de su consecuente desfundamentación de toda pretensión de acceso objetivo, no valorativo, neutral, a la realidad, implicaciones relativistas: a saber, una desfundamentación del conocimiento en cuanto tal (conocer consistiría propiamente en el establecimiento de las condiciones para el aumento de poder de una perspectiva, quedando fuera de cuestión toda pretensión de verdad intersubjetiva) y una yuxtaposición de perspectivas que en cada caso generan experiencias cualitativamente diferentes ${ }^{3}$. La razón de esta deriva relativista es la particular antropología nietzscheana, que en el interior de la especie humana concibe las diferencias entre los tipos humanos como comparables a las diferencias entre las especies en los niveles menos desarrollados de la evolución biológica. Si, en última instancia, cada tipo humano se diferencia de los demás como si de otras especies se tratase, entonces resulta claro que no cabe ninguna comunicación ni intersubjetividad y que las diversas experiencias del mundo serán inconmensurables, sin posibilidad de contraste ni influjo mutuo. Cada proceso de conocimiento estaría al servicio del acrecentamiento del poder de esa determinada perspectiva, aquí es donde se pondría en juego su validez. En definitiva, conocer consistiría propiamente en esto, en un proceso de imposición sobre la naturaleza al servicio del aumento del poder de la propia perspectiva, y no en la consecución de un conocimiento verdadero de las cosas y el acceso a verdades contrastables ${ }^{4}$.

\footnotetext{
2 F. Nietzsche, Sämtliche Werke. Kritische Studienausgabe, Berlín/Nueva York, Walter de Gruyter/Dtv, 1988, vol. 12, p. 315, 7[60].

3 Ver ibid., vol. 12, p. 313, 7[54] y vol. 13, p. 302, 14[122].

4 Ver ibid., vol. 12, p. 385, 9[91] y vol. 13, p. 271, 14[93].
} 
Pero esta deriva relativista es compensada, por un lado, por la particular concepción nietzscheana de los distintos tipos humanos, que deja abierta la posibilidad (respaldada por textos del propio Nietzsche) de conferir al tipo humano superior y, en definitiva al superhombre del porvenir, la capacidad, gracias a su peculiar perspectiva definida por la especificidad de su fisiología, de acceder a un conocimiento no distorsionado de la realidad. Así, el superhombre, esa figura del porvenir que constituye el anhelo de Nietzsche, "concibe la realidad tal como ella es: es suficientemente fuerte para hacerlo, no es una especie de hombre extrañada de la realidad, es la realidad misma, encierra todavía en sí todo lo terrible y problemático de ésta"5.

Por otro lado, y más relevante para nuestra problemática, el último Nietzsche concibió la genealogía de la moral como una forma de conocimiento de la historia efectivamente acaecida de la moral que no cabe ser calificada de relativista. Nietzsche concibe la genealogía a partir de la mutua implicación de conocimiento y perspectivismo: su tesis es que sólo desde una determinada perspectiva y desde el diagnóstico del presente que ella realiza, cabe una aproximación al pasado capaz de efectuar un conocimiento del mismo con efectos de sentido en el plano práctico para los agentes en el presente. Esto ya aparecía claramente en su segunda Consideración Intempestiva, que efectúa una dura polémica con el historicismo como concepción positivista y cientificista del conocimiento histórico y reivindica una noción de conocimiento histórico al servicio de la vida ${ }^{6}$. En continuidad con la posición plasmada en esta obra, en sus reflexiones tardías sobre la genealogía de la moral resulta patente que el objetivo de la genealogía de problematizar una evidencia imperante en el presente a partir de una reconstrucción del proceso irracional, conflictivo, contingente, por el que ha llegado a convertirse en tal evidencia, tiene como sustento no un sujeto de conocimiento que adopta una actitud neutral, objetiva, desinteresada, sino un sujeto impuro de conocimiento, es decir, un sujeto definido por una determinada perspectiva sobre la situación del presente y ubicado de un modo específico en el seno de los conflictos y antagonismos que definen su situación histórica. Lo singular en la concepción nietzscheana de la genealogía de la moral es que lo que la capacita para realizar una reconstrucción, con posibles efectos prácticos sobre los agentes sociales, de los procesos que han dado lugar a las evidencias del presente es, junto a su orientación por un determinado diagnóstico de su situación histórica efectuado desde una perspectiva específica, su metodología rigurosa y su apoyo en determinadas ciencias particulares. Es tal imbricación de diagnóstico crítico del presente, que lo considera como punto de partida problemático de la investigación histórica, y de una metodología histórica atenta a las

\footnotetext{
5 F. Nietzsche, Ecce homo, Madrid, Alianza, 1971, p. 128.

6 F. Nietzsche, Sobre la utilidad y el perjuicio de la historia para la vida, Madrid, Biblioteca Nueva, 1999.
} 
transformaciones de sentido de las prácticas sociales lo que la capacita para hacerse cargo de procesos históricos no teleológicos, en los que no se plasma, desarrolla y constituye un sentido que culmina en el presente, sino que están marcados por la contingencia, la discontinuidad, las posibles inversiones en la correlación de fuerzas enfrentadas en cada momento histórico ${ }^{7}$.

De este modo, perspectivismo y pretensión de rigurosidad metódica no están reñidas en la genealogía, sino que constituyen el sustento de su productividad epistemológica y de su efectividad práctica. El genealogista es parte de una de las posiciones enfrentadas entre sí en el presente y es en virtud del diagnóstico de la realidad que comparte con tal posición que adquiere coherencia y sentido su labor de aproximación al pasado para deconstruir, a partir de la exposición histórica, una idea, un valor o una institución tenida en el presente como evidente y que actúa como un sustento legitimador de un marco social restrictivo y coercitivo. Tal labor adquiere pues sentido en cuanto que es realizada como contribución a la ilustración y al refuerzo de esa posición en el presente que sufre una situación dominada en el régimen de poder vigente: en ello reside sus efectos de sentido, sus efectos prácticos en la coyuntura de su presente. En todo caso, de lo expuesto se derivaría que la genealogía de la moral accede a verdades, verdades que ciertamente trascienden la identificación platónica de verdad-bien-belleza, pero verdades contrastables, públicas, comunicables y, por ello, inmorales, feas y blasfemas para las posiciones contrincantes: los genealogistas de la moral "se han educado para sacrificar todos los deseos a la verdad, a toda verdad, incluso a la verdad simple, áspera, fea, repugnante, no-cristiana, no-moral... Pues existen verdades tales"8.

La concepción de la genealogía de la moral del último Nietzsche es posiblemente la pervivencia en su pensamiento maduro de ideas forjadas en lo que se ha denominado su periodo ilustrado, sobre todo en su obra Humano, demasiado humano. Aquí formula los contornos de lo que denomina una filosofia histórica que, apoyada en las ciencias naturales, pretende mostrar cómo "algo puede nacer de su contrario, por ejemplo, lo racional de lo irracional, lo sensible de lo muerto, la lógica de la ilógica, la contemplación desinteresada del querer ávido, el altruismo del egoísmo, la verdad de los errores", cerrando así el abismo ontológico entre ambos planos abierto por la filosofía metafísica tradicional ${ }^{9}$. Esta filosofía histórica efectuaría una Entstehungsgeschichte (una historia del surgimiento o de la génesis) del pensamien-

\footnotetext{
7 Ver, sobre todo, F. Nietzsche, La genealogía de la moral, Madrid, Alianza, 1973, pp. 24 y 87-91. Sobre el sustento teórico y metodológico de la genealogía, ver G. Cano, Nietzsche y la crítica de la modernidad, Madrid, Biblioteca Nueva, 2001. Sobre este tema puede verse también mi trabajo "Los frágiles cimientos del presente. La genealogía nietzschena y la verdad de la historia", en Estudios Nietzsche, $\mathrm{n}^{\circ}$ 3, Málaga, 2003, pp. 141-161.

8 Nietzsche, La genealogía de la moral, ed. cit., p. 30.

9 Ver F. Nietzsche, Humano, demasiado humano, Madrid, Akal, 1996, vol. I, p. 23.
} 
to, que reconstruiría el proceso de constitución de la representación del mundo que compartimos en cuanto especie, con objeto de posibilitar un cuestionamiento de su evidencia e incuestionabilidad (por ejemplo, de la evidencia cognitiva de que lo real está compuesto de cosas con una identidad consistente) ${ }^{10}$. Lo que nos interesa aquí es el modo en que el último Nietzsche, en el que se da una radicalización de la deconstrucción de la categoría de verdad y de conocimiento, se mantiene la pretensión de un conocimiento histórico de la moral acaecida que aspira, al mismo tiempo, a la efectividad práctica sobre el presente (a la ilustración y respaldo de una de las posiciones enfrentadas en el antagónico campo social) y a la rigurosidad metodológica (y pretende, por tanto, ser conocimiento verdadero).

\section{La situación hermenéutica como perspectiva de la interpretación en M. Heidegger y H.-G. Gadamer}

En la hermenéutica, esta vinculación constitutiva de la experiencia y el conocimiento del mundo a una determinada perspectiva es tematizada con la categoría de situación hermenéutica. Ahora bien, la noción de situación hermenéutica en Heidegger y Gadamer se hace cargo del significado del perspectivismo en cuanto perspectivismo histórico. Tanto en Heidegger como en Gadamer, la situación hermenéutica de un acto de conocimiento o de interpretación está constituida por aquello que constituye el punto de mira, lo que orienta la mirada en una determinada dirección, delimitándola y confiriéndole así un determinado perímetro, un determinado horizonte. ${ }^{11}$ La situación hermenéutica limita así las posibilidades de visión, pero es la condición de posibilidad de que efectivamente se pueda ver algo, pues constituye el lugar de la mirada, su dirección y el círculo de su alcance, su horizonte. Define pues una perspectiva determinada. Pero lo que tenemos aquí es una forma de perspectivismo histórico, pues la perspectiva definida por la situación hermenéutica remite a un determinado momento histórico en su relación con el pasado, en concreto, con el pasado actualizado en el presente en forma de tradición, y con el

\footnotetext{
10 Ibid., pp. 37-8.

11 Ver M. Heidegger, Interpretaciones fenomenológicas sobre Aristóteles. Indicación de la situación hermenéutica, Madrid, Trotta, 2002, pp. 29-30. Ver además, H.-G. Gadamer, Verdad y método I, Salamanca, Sígueme, 1991, pp. 372 y 376 y, del mismo autor, Verdad y método II, Salamanca, Sígueme, 2000, p. 57.

12 Esto ha sido expuesto de manera aclaratoria por Ramón Rodríguez: "es la mutua interrelación de los momentos estructurales de «proyección» (Entwurf) y «arrojamiento» (Geworfenheit), con su temporalidad peculiar, la que funda ontológicamente el carácter finito, situado, de la comprensión. Que la existencia humana histórica es constitutivamente el poder-ser de un haber-siempre-ya-sido pone justamente de manifiesto que la condición limitativa, temporal-histórica, de la comprensión es precisamente lo que la hace posible, lo que la potencia. De ahí la importancia radical de la idea de situación
} 
porvenir al que tal situación histórica de un modo u otro se abre ${ }^{12}$.

Lo que define la situación hermenéutica tanto en Heidegger como en Gadamer son "representaciones, creencias o conceptos" 13 de carácter público, compartidos por los individuos en un momento histórico determinado y que forman parte constitutiva de su modo de existencia cotidiana: son "preconcepciones"14, prejuicios, cuya procedencia es la tradición. Heidegger y Gadamer comparten la tesis de que la situación hermenéutica de todo acto interpretativo está constituida por los prejuicios presentes en el intérprete, transmitidos por la tradición de la que forma parte y a la que en definitiva trata de comprender, pero divergen en cuanto al significado del papel que la tradición juega en la experiencia cotidiana, es decir, sin haber pasado por la crítica filosófica ${ }^{15}$. En Gadamer no se problematiza el carácter constituyente de la tradición para la perspectiva del intérprete, en tanto que la tradición y los prejuicios transmitidos son considerados en primer lugar como ontológicamente constitutivos de toda perspectiva interpretativa, por lo que no cabe ni una clarificación ni una crítica integral de los mismos, y en segundo lugar como poseyendo un papel productivo en la interpretación, pues es gracias a los prejuicios depositados en el intérprete por su pertenencia a una tradición que éste puede establecer un diálogo con dicha tradición.

En el primer Heidegger, en cambio, el significado de la tradición y de los prejuicios transmitidos por ella en la constitución de la situación hermenéutica, desde la que la hermenéutica del Dasein afronta su tema, es más problemático. Pues el primer Heidegger considera que la tradición aparece primeramente como imperando en el ámbito de lo públicamente interpretado, que es de donde el Dasein recibe los prejuicios que contaminan su autopercepción y distorsionan el intento de realizar un acceso hermenéutico al Dasein. La tradición que constituye la situación hermenéutica de partida de una "hermenéutica fenomenológica de la facticidad"16 es una tradición devenida inauténtica y los prejuicios que trasmite distorsionan la posibilidad de que el Dasein se dé en su ser propio, tanto a un acceso fenomenológico como a la autointerpretación espontánea del Dasein en cuanto tal. Por ello, el punto de partida de la hermenéutica del Dasein del primer Heidegger es abiertamente distinto

\footnotetext{
hermenéutica, que recoge precisamente el hecho de que la anticipación del comprender no es una estructura meramente formal, un movimiento vacío, sino materialmente determinado por las posibilidades ya realizadas, que se constituyen en el horizonte de lo posible. De esta forma, toda intelección y enunciación de un estado de cosas está precedido, limitado y a la vez posibilitado por la situación en que se origina. Gadamer ha llevado esta condición limitativa del comprender a la problemática del conocimiento histórico, resultando la vinculación de la anticipación de sentido a la pertenencia a una tradición, contra el ideal objetivista que pervive en el historicismo diltheyano." R. Rodríguez, Del sujeto y la verdad, Madrid, Síntesis, 2004, pp. 199-200.

13 Rodríguez, La transformación hermenéutica de la fenomenología, Madrid, Tecnos, 1997, p. 116.

14 Ibid.

15 Ver R. Rodríguez, Hermenéutica y subjetividad, Madrid, Trotta, 20102, pp. 157 y 175.

16 Heidegger, Interpretaciones fenomenológicas sobre Aristóteles, ed. cit., p. 47.
} 
del de la hermenéutica filosófica de Gadamer: el primer movimiento de la hermenéutica del Dasein consiste en una destrucción de la tradición ${ }^{17}$, tal como impera en el inauténtico espacio de lo público y una deconstrucción de los prejuicios transmitidos ${ }^{18}$. Todo ello no para disolver todo vínculo con la tradición y liberar la mirada de todo horizonte, sino para ganar una vinculación genuina con el pasado, es decir, con las experiencias originarias que constituyen la base de los conceptos transmitidos por la tradición, experiencias difuminadas, encubiertas, en el imperar actual de tales conceptos, transmitidos como moneda usada, como meros prejuicios irreflexivos 19: "Antes que nada, la fenomenología debe liberarse gradualmente de la tradición con el fin de acceder a la filosofía del pasado y apropiársela verdaderamente. (...) En el respectivo presente histórico [en el que se mueve una investigación, JMR] existe el peligro de obstruir la historia, de no descubrirla, sino de hacerla inaccesible. Liberarse de tales prejuicios y meditar nuevamente sobre las condiciones que permiten aprehender el pasado es tarea de la crítica. La investigación filosófica implica la crítica del presente. Es una apertura originaria del pasado" 20. Se trata de "liberar el pasado, de tal manera que se vea que el pasado es el lugar donde encontramos las verdaderas raíces de nuestra existencia"21. El desmontaje de la tradición pretende recobrar así lo histórico originario encubierto: "Desmontar quiere decir aquí: retorno a la filosofía griega, a Aristóteles, para ver cómo lo que era originario decae y queda encubierto, y para ver cómo nosotros estamos en medio de esta caída. En correspondencia a nuestra posición se trata de volver a configurar de nuevo la posición originaria, es decir, una posición que en correspondencia a una situación histórica diferente es otra y, sin embargo, la misma"22. Para llevar a cabo esta tarea de confrontación con la tradición devenida inauténtica, Heidegger apela a la necesidad de una crítica histórica radical: "Se trata de llegar a aprehender la cosa libre de encubrimientos (...). Para ello es necesario sacar a la luz la historia del encubrimiento. Hay que remontar la tradición del cuestionar filosófico hasta las fuentes del asunto. Hay que desmontar la tradición. Sólo de esa manera resultará posible un planteamiento originario del asunto. (...) Eso hoy en

\footnotetext{
17 Ver M. Heidegger, Introducción a la investigación fenomenológica, Madrid, Síntesis, 2008, pp. 1256 y 214.

18 En este punto, el pensamiento del primer Heidegger (sobre todo en sus Vorlesungen previas a Ser y tiempo) se encuentra más próximo a las posiciones ilustradas y de crítica de la ideología que el de Gadamer, que aparece como una posición más conservadora y desproblematizadora de la tradición.

19 Aquí nos atenemos al significado con el que la tradición aparece en el inauténtico espacio de lo público. En cambio, la tradición puede adquirir también un significado propio, genuino: ello ocurre en el acto de resolución del Dasein, tal como es expuesto en el parágrafo 74 de Ser y tiempo. En el apartado siguiente se tratará el significado propio que la tradición asume en esta obra.

20 M. Heidegger, Interpretaciones fenomenológicas sobre Aristóteles, ed. cit., pp. 68 y 95.

21 Ibíd., p. 95.

22 M. Heidegger, Ontología. Hermenéutica de la facticidad, Madrid, Alianza, 1999, p. 100.
} 
día sólo es posible por medio de una crítica histórica radical. Dicha crítica (...) es una tarea fundamental de la propia filosofía" 23.

En todo caso, tanto en Heidegger como en Gadamer se postula una aclaración o una elaboración de la situación hermenéutica ${ }^{24}$, es decir, una confrontación con nuestros prejuicios incorporados con objeto de ganar el horizonte adecuado para la comprensión. Si en Heidegger ello tiene un significado crítico con la tradición devenida inauténtica imperante en el espacio de lo público (Heidegger plantea la necesidad de una "hermenéutica de la situación" que "debe hacer transparente la propia situación" 25$)$, en el caso de Gadamer, la elaboración de la situación hermenéutica pretende que reflexionemos sobre los prejuicios que orientan nuestra interpretación, no para criticarlos, sino para devenir conscientes del grado en que la tradición acontece en nuestros actos de comprensión e interpretación, es decir, para devenir conscientes de nuestra finitud radical en cuanto intérpretes.

En Heidegger y Gadamer el concepto de situación hermenéutica está propuesto en contraposición a la idea de un acceso a la vida histórica liberado de todo carácter situado, perspectivista, un acceso teórico-científico carente de contaminación fáctica, acceso defendido supuestamente por la fenomenología transcendental de Husserl (según Heidegger) y por el historicismo de Dilthey y por la Ilustración (según Gadamer). Para Heidegger, en concreto, "la pretensión de un observar exento de perspectiva" implica "la falta de crítica", pues tal pretensión "eleva la falta de crítica a principio, haciéndola figurar explícitamente entre las consignas de la en apariencia suprema idea de cientificidad y objetividad, contribuyendo así a extender una ceguera radical" 26 . La noción de situación hermenéutica le permite sostener a Heidegger que todo intento de interpretación y conocimiento de lo histórico está constitutivamente orientado en una dirección determinada a partir de la situación de partida del intérprete, a partir de la problemática que define su presente histórico. Ello orienta la mirada del intérprete de modo específico, constituye en definitiva una perspectiva. Para Gadamer, en cambio, las interpretaciones están estructuradas a partir de la presencia en ellas de lo transmitido por la tradición, están constituidas por el acaecer de la tradición en el modo de ser cotidiano del intérprete, definido por su situación histórica específica, y en todo acto de interpretación suyo. La forma de perspectivismo que se tematiza ambos casos es, pues, un perspectivismo histórico, en tanto que las diversas perspectivas definidas por las posibles situaciones herme-

\footnotetext{
23 Ibid., p. 99. De ahí que "contra el peligro del encubrimiento implícito en la publicidad y contra el dominio del estado interpretativo consagrado por el uso, el Dasein tiene que recurrir siempre y cada vez de nuevo a la crítica para apropiarse las posibilidades de una adecuada experiencia originaria." M. Heidegger, El concepto de tiempo (Tratado de 1924), Barcelona, Herder, 2008, p. 53.

24 Ver M. Heidegger, Interpretaciones fenomenológicas sobre Aristóteles, ed. cit., p. 31 y H.-G. Gadamer, Verdad y método I, ed. cit., p. 373.

25 M. Heidegger, Interpretaciones fenomenológicas sobre Aristóteles, ed. cit., p. 30.

26 M. Heidegger, Ontología. Hermenéutica de la facticidad, ed. cit., pp. 106-7.
} 
néuticas están constituidas por los modos diversos de actualizarse o acaecer la tradición en la vida de los intérpretes, es decir, por la relación específica del legado del pasado con cada presente (y por la apertura al porvenir que tal relación sustenta). Es efectivamente cada presente, en su relación con el pasado propio, el que constituye en cada caso una situación hermenéutica específica y en consecuencia una perspectiva determinada para el comprender. Siendo así, todos los miembros de una generación 27 , todos los que comparten un determinado presente, comparten a su vez una situación hermenéutica y comparten, por lo tanto, una perspectiva análoga.

\section{Perspectiva e interés de la teoría crítica}

Esta concepción de la situación hermenéutica y de la perspectiva del comprender tanto en el primer Heidegger como en Gadamer en términos de situación histórica posibilita en efecto su pretensión de articular, sobre un concepto así de perspectiva compartida por los intérpretes de una época, una teoría del comprender que logre soslayar la deriva hacia una concepción de las perspectivas como radicalmente individuales, que conduciría a un pluralismo inconmensurable de las interpretaciones y que llevaría a su vez no sólo a un relativismo explícito sino a la consagración de un estado de nihilismo hermenéutico efectivo, en el que toda (o ninguna) interpretación puede valer. Esto, que puede ser entendido como una ganancia respecto a determinadas lecturas influyentes de Nietzsche, implica más bien un retroceso respecto al modo en que éste concibió el ensamble entre perspectivismo y conocimiento en la genealogía (dejo de lado sus reflexiones, algunas de ellas filosóficamente muy especulativas, en torno a las implicaciones derivables del carácter perspectivista de toda experiencia) ${ }^{28}$. Pues para Nietzsche en el seno del propio presente se enfrentan diversas perspectivas y sólo caben accesos epistemológicos al pasado desde el seno de alguna de ellas, en tanto que no existirían accesos epistemológicos elevados por encima de los conflictos que estructuran el presente. No pretendo atribuir a Nietzsche (ni sostener yo mismo) que cada posición social (cada clase y grupo social) posee por su posición en la estructura social una determinada perspectiva que constituye su particular situación hermenéutica en su respectiva apertura al mundo, es decir, no pretendo afirmar una especie de determinismo económico-social sobre el conocimiento, que definiría a partir de los diferentes lugares sociales la existencia de una serie de perspectivas epistemológicas inconmensurables entre sí entre las que no cabría comunicación alguna. Lo que me parece importante del planteamiento de Nietzsche, y no está recogido en las formulaciones de

\footnotetext{
27 En un material póstumo del primer Heidegger se sostiene: "El respectivo Dasein es al mismo tiempo siempre una generación." Heidegger, El concepto de tiempo (Tratado de 1924), ed. cit., p. 113. 28 Ver Nietzsche, Sämtliche Werke. Kritische Studienausgabe, ed. cit., vol. 13, p. 373-4, 14[186].
} 
Heidegger y Gadamer, es la concepción de lo social como conflicto, habitualmente soterrado pero a veces abierto, entre posicionamientos antagónicos 29 . No me interesa el modo en que Nietzsche caracterizó tal conflicto (entre el platonismo-judeocristianismo, por un lado, y los valores aristocráticos y la concepción dionisíaca del mundo, por otro, o entre tipos inferiores y superiores desde un punto de vista fisiológico-espiritual), sino su caracterización del contexto en el que se plantea la cuestión del acceso historiográfico al pasado como un contexto fracturado por los conflictos entre posiciones enfrentadas en el presente, sin que exista una posición más allá, exterior, a tal plano de conflictividad. Frente a Nietzsche tengo que sostener que tal situación de conflicto se sustenta no en el choque entre visiones del mundo o entre tipos fisiológico-espirituales, sino en la multiplicidad de asimetrías que estructuran las sociedades modernas, desde el ámbito económico hasta el político y socio-cultural.

Para Nietzsche, esta escisión de posiciones enfrentadas no supone un impedimento para el conocimiento del pasado, sino, precisamente, la condición de posibilidad para una forma de conocimiento con pretensión de efectividad práctica sobre el presente, pues lo que se considera como objeto relevante de conocimiento y la identificación de los procesos de transformación histórica significativos están definidos en cada caso a partir de un diagnóstico específico, realizado desde una determinada perspectiva, de la situación del presente. Esta situación de conflicto en el presente no implica la imposibilidad de comprensión o comunicación entre las diversas posiciones (no estamos ante una constitución diferencial de perspectivas ontológicamente distintas hasta el punto de que no habría comunicación posible entre las mismas). Precisamente porque la comunicación, la discusión, el influjo a través del discurso y a través de argumentos, razones y conocimientos es posible, emprende el genealogista la deconstrucción histórica de un determinado valor que legitima en el presente el poder de los grupos hegemónicos: pretende reforzar con argumentos y conocimientos la posición de la que forma parte, combatiendo los mecanismos de autolegitimación de las posiciones a las que se opone, al enfrentarlas a su ausencia de fundamento firme y seguro, mostrado por la genealogía como un constructo, una ficción. Los conocimientos a los que accede el genealogista pretenden tener un carácter público, comunicable, discutible, polémico y, por lo tanto, resultar convincentes incluso para las posiciones con las que se enfrenta: efectivamente, las mismas comprenden perfectamente el significado de tales conocimientos al percibirlos en su carácter blasfemo para ellas ${ }^{30}$.

\footnotetext{
29 En sus estudios históricos de los años setenta M. Foucault ha hecho fructífero el paradigma teórico del conflicto. Según Foucault, "se puede hablar del carácter perspectivo del conocimiento porque hay batalla y porque el conocimiento es el efecto de esa batalla." Ver M. Foucault, La verdad y las formas jurídicas, Barcelona, Gedisa, 1992, pp. 30-1.

30 Ver F. Nietzsche, Aurora, Barcelona, Alba Editorial, 1999, §1, p. 19.
} 
Esta caracterización del contexto que funda la existencia de una diversidad de perspectivas a partir de la trama de conflictos existentes permite redefinir los elementos que constituyen la situación hermenéutica. Pues ahora lo constitutivo de la situación hermenéutica no es sólo la tradición, aunque su papel sea central, tal como veremos más adelante (ni tampoco algo así como la posición social, que determinaría la perspectiva epistémica de cada grupo). En una situación de conflicto, los elementos que constituyen cada una de las perspectivas confrontadas son sobre todo factores ético-políticos, los cuales no son necesariamente prejuicios transmitidos por la tradición, sino que pueden adoptar un carácter explícito y reflexivo como principios orientadores de la acción. Aquí la apropiación de la situación hermenéutica toma la forma de una explicitación de (y una confrontación con) las pretensiones normativas que conforman la propia perspectiva. Estos factores ético-políticos que definen la situación hermenéutica configuran en cada caso un específico interés, cuyo papel es fundamental en la orientación de los actos de comprensión y de conocimiento de la perspectiva concreta.

El cúmulo de factores ideológicos, éticos y políticos que definen una determinada situación hermenéutica y constituyen una perspectiva específica se plasma en la articulación de un determinado interés en cuanto orientador de los modos de acceso del sujeto a su asunto de consideración. Tal interés posee en consecuencia también un carácter ético-político y así ha sido tematizado en el seno de la teoría crítica: en sus escritos de los años treinta, tanto Horkheimer como Marcuse sostuvieron que a la teoría crítica la impulsaba un determinado interés, a saber, un interés por la liberación, por la emancipación ${ }^{31}$. También Habermas, a final de los años sesenta, identificó lo específico de la teoría crítica a partir de su interés constitutivo por la emancipación ${ }^{32}$. Aquí resulta significativo que, aunque a diferencia de Horkheimer y Marcuse, afrontó el estatuto de tal interés en el marco de una reflexión de tipo antropológico-transcendental sobre los intereses rectores del conocimiento, para la cual los intereses que orientan al conocimiento científico y a las ciencias histórico-hermenéuticas serían cuasi-transcendentales, es decir, constitutivos, en sentido antropológico, de los modos de ocupación propios del ser humano con los diferentes ámbitos de la realidad, le confirió en cambio al interés por la emancipación un carácter diferente. Le atribuyó, como hicieron Horkheimer y Marcuse, un estatuto histórico. Es decir, incluso en su proyecto teórico más explícitamente antropológico-transcendental (convergente con la antropología del conocimiento en la que estaba embarcado Apel aquellos años), Habermas, como antes

\footnotetext{
31 Cf. H. Marcuse, "El concepto de esencia", en id., La agresividad en la sociedad industrial avanzada, Madrid, Alianza, 1984, p. 56 y M. Horkheimer, Teoría tradicional y teoría crítica, Barcelona, Paidós, 2000, pp. 41 y ss.

32 Ver Habermas, Ciencia y técnica como "ideología”, Madrid, Tecnos, 1990, pp. 159-181 y, del mismo autor, Conocimiento e interés, Madrid, Taurus, 1989.
} 
Horkheimer y Marcuse, rechaza fundar el interés de la teoría crítica en términos antropológicos, sino que efectúa una destranscendentalización de tal interés y defiende una interpretación del mismo en términos históricos (es decir, se trataría de un interés originado históricamente, o sea, contingentemente, y no sería constitutivo ni de la especie humana ni de la razón) y en términos ético-políticos (su surgimiento hay que enmarcarlo en el seno de los procesos de conflicto que constituyen la continuidad del decurso histórico hasta nuestros días) ${ }^{33}$.

De esta manera, el interés que orienta a la teoría crítica aparece como fraguado en el seno de una determinada perspectiva de entre las enfrentadas en el conflictivo escenario social. Tal interés define la particular situación hermenéutica de una determinada posición en el seno de los antagonismos vigentes. Por lo tanto, cabe una apropiación, una aclaración del mismo, en el sentido de hacerlo reflexivo en un proceso de confrontación con y justificación de su pretensión de validez. El interés que articula la situación hermenéutica de la teoría crítica no es así un mero prejuicio que distorsiona su acceso a lo social o lo hipoteca como necesariamente ideológico, en el sentido de generador de una falsa conciencia. Tal interés puede y debe devenir reflexivo y cabe ser confrontado en su pretensión de validez. Naturalmente un interés tal delimita el lugar desde el que se accede a lo social, orienta la dirección del acceso y define el perímetro de su mirada pero, al mismo tiempo, es la condición de posibilidad de un acceso a lo social ético-políticamente significativo para las posiciones interesadas en un ordenamiento cualitativamente diferente de la estructura social en una dirección superadora de los estados de injusticia y dominio considerados como intolerables. Resulta patente que un interés así definido no caracteriza a una perspectiva meramente individual frente a un sinnúmero de otras perspectivas articuladas en torno a intereses cualitativamente diferentes. Entendido así, el interés del que hablamos configura la situación hermenéutica (y aquí habría otra analogía con Nietzsche) de un tipo determinado de perspectivas, a saber la de las posiciones que en el seno de los conflictos vigentes experimentan como intolerables las asimetrías existentes y aspiran a una modificación de la realidad en una dirección justa.

A partir del significado otorgado aquí al interés en la definición de la situación hermenéutica del acceso teórico crítico a lo social, aparece a una nueva luz la contraposición que el primer Heidegger realizó entre los modos de acceso teórico y hermenéutico a la existencia humana (lo que entonces denominó vida fáctica) y la que estableció Lukács en Historia y conciencia de clase entre el enfoque teórico-científico burgués y el dialéctico sobre la realidad histórico-social: ambos contrapusieron un enfoque objetivante, pretendidamente neutral desde un punto de vista valorativo, realizado en la actitud del observador supuestamente no comprometido en tér-

33 Ver J. Habermas, Conocimiento e interés, op. cit., pp. 324-5. 
minos ético-políticos con el asunto del que se ocupa y un enfoque capaz de hacerse cargo de la significación, la dinamicidad y la problematicidad de la realidad a la que pretende acceder en tanto que enfoque comprometido con tal realidad 34 . Si en Lukács, el enfoque dialéctico tiene aún una base especulativa, en tanto que se afirma como el enfoque sustentado en la perspectiva epistemológica y metafísicamente privilegiada que es la perspectiva del proletariado, en tanto que sujeto-objeto idéntico de la historia, en Heidegger en cambio el enfoque hermenéutico sobre la existencia humana se sabe impulsado por la misma preocupación o Sorge por la existencia que caracteriza a la propia existencia humana ${ }^{35}$. El primer Heidegger confrontó dos modos de acceso a la existencia: uno es la "captación teórica de tipo objetivador" 36 , que puede pretender acceder a su asunto a partir de su ubicación en el seno de una previa anticipación del mismo como objeto, como teniendo el modo de ser del estar-ahí. Este modo de captación teórica pierde su asunto, es decir, la existencia, en su modo de ser propio, en cuanto preocupación. Por ello, el sentido de ser de la vida fáctica sólo se abre "a partir de la experiencia fundamental de un preocuparse de sí mismo" 37 . El acceso capaz de hacerse cargo del sentido de ser de la existencia es, en primer lugar, histórico y, en segundo lugar, está caracterizado por la preocupación de sí mismo y está vinculado inextricablemente a la preocupación de sí de la propia existencia a la que pretende acceder: "el fenómeno de la existencia sólo se abre a un cumplimiento activo de la experiencia dotado de una aspiración histórica radical, que no se orienta a una posición de mera contemplación, ni a un modo de ordenar objetivador por regiones, sino que está esencialmente preocupado de sí mismo"38. La preocupación por la existencia que impulsa a la hermenéutica es así claramente un componente de tipo moral (aunque en el planteamiento de Heidegger tal componente permaneciera innominado y no tematizado en cuanto tal) que la distingue cualitativamente de toda forma de autopercepción teórica cientificista o teoricista. Este componente moral aparece en la formulación de la teoría crítica que articularon Horkheimer y Marcuse en los años 30 en forma de una preocupación explícita por la felicidad concreta y sensible de los seres humanos, preocupación que al sustentar un interés en la abolición de las condiciones his-

\footnotetext{
34 Ver M. Heidegger, La idea de la filosofía y el problema de la concepción del mundo, Barcelona, Herder, 2005 y, del mismo autor, "Anotaciones a la Psicología de las visiones del mundo de Karl Jaspers”, en id., Hitos, Madrid, Alianza, 2000, pp. 15-47 y G. Lukács, Historia y consciencia de clase, México, Grijalbo, 1969.

$35 \mathrm{Me}$ ocupo de este tema en Crítica e historicidad, Barcelona, Herder, 2010, pp. 231-5 y en J.M. Romero (ed.), H. Marcuse y los orígenes de la teoría crítica, Madrid, Plaza y Valdés, 2010, pp. 59-68. 36 Heidegger, "Anotaciones a la Psicología de las visiones del mundo de Karl Jaspers", en id., Hitos, ed. cit., p. 27.

37 Ibid., p. 37.

38 Ibid., p. 38
} 
tóricas que sistemáticamente la frustran, posee por tanto explícitas implicaciones políticas 39 .

\section{Situación hermenéutica y tradición}

Hemos visto que, tanto para Heidegger como para Gadamer, los parámetros que constituyen la situación hermenéutica están definidos por la tradición, aunque ello ocurre en cada uno de ellos de un modo distinto. A diferencia de Gadamer, en las Vorlesungen de los años veinte del primer Heidegger pervive de alguna manera la actitud crítica ilustrada frente a la influencia irreflexiva de la tradición en nosotros en forma de prejuicios que orientan de un modo incontrolado y distorsionado nuestra relación con el pasado y con el presente y, en definitiva, con nosotros mismos. Esta actitud crítica frente a la tradición tal como impera ésta de modo dominante en el presente, tanto en el espacio público cotidiano como a través del dominio de la filosofía tradicional, que pretende realizar una destrucción o un desmontaje de la misma, se sostiene en un diagnóstico específico acerca del presente de las sociedades modernas, en las cuales la tradición se ha vuelto inauténtica, es decir, ha perdido el contacto con las experiencias originarias a las que debe su surgimiento. De ahí que la destrucción de la tradición en Heidegger consista en un ejercicio de deconstrucción del modo en que se usan y comprenden comúnmente los conceptos recibidos y un intento de recobrar las experiencias originarias que dieron lugar a ellos. En este sentido, la destrucción de la tradición proclamada por Heidegger está al servicio de la constitución de una relación genuina con el pasado como legado, como tradición auténtica, de la que recibir indicaciones para un planteamiento adecuado de los problemas a los que nos enfrentamos en el presente.

Algo análogo ocurre en el planteamiento de Ser y tiempo en el momento en que el Dasein entra en estado de resolución 40 : es precisamente en el estado de resolución, en el que el Dasein ha logrado desvincularse de las posibilidades de existencia ofrecidas como las únicas disponibles por el espacio público de lo anónimamente interpretado, en el que finalmente se confronta con la tarea de apropiarse de sus posibilidades genuinas, es decir, no determinadas por alguna instancia externa, sino elegidas por él mismo, y, en definitiva, en el que el Dasein se hace cargo de su propia existencia como tarea y responsabilidad suya, que el pasado se le presenta de un modo nuevo. Ya no aparece como un cúmulo de hechos, datos y fechas, objetivable por la historia positivista y por el historicismo, sino de un modo relevante para el Dasein desde un punto de vista práctico-existencial: como legado de posibilidades de existencia realizadas, de entre las cuales puede elegir aquéllas que quiere hacer

39 Desarrollo este tema en mi trabajo "La problemática de la historicidad en el primer H. Marcuse", en Pensamiento, Madrid, 2013, vol. 69, $\mathrm{n}^{\circ}$ 259, pp. 331-350.

40 M. Heidegger, Ser y tiempo, Madrid, Trotta, 2003, pp. 399 y ss. 
propias. Así surge el modo genuino de ser de la tradición: ante una situación en la que el Dasein, por un lado, ha sido liberado del peso coactivo de las posibilidades de existencia vigentes $\mathrm{y}$, por otro, se ve abocado a afrontar la tarea de hacerse cargo responsablemente de su existencia, en una situación, en resumidas cuentas en la que el Dasein está inmerso en una problemática que podríamos llamar práctico-existencial, el pasado deviene tradición genuina, a saber, legado, transmisión de posibilidades que el Dasein puede hacer suyas.

Esta dimensión crítica y cuando menos reflexiva de la problemática de la tradición en las Vorlesungen del primer Heidegger, ya un tanto difuminada en Ser y tiem$p o^{41}$, resulta poco visible en Gadamer, posiblemente porque en él el concepto de tradición está forjado no tanto en diálogo con tales reflexiones primerizas de Heidegger sino quizá a partir del concepto de tradición como legado de Ser y tiempo y, sobre todo, a partir de motivos posteriores a la Kehre, en concreto, a partir de las ideas del Heidegger maduro en torno al concepto de Ereignis, en cuanto acontecer propio del ser ${ }^{42}$. Efectivamente, en Gadamer la tradición es un acaecer de sentido que abarca al intérprete como un momento suyo, respecto del cual posee primacía. Tal concepción lleva a caracterizar los actos concretos de comprensión del intérprete no como actos propiamente suyos, sino como modos de acontecer de la propia tradición, indisponible para el intérprete, y que éste vive como un acontecimiento, un hacerse presente un sentido que tiene un fuerte componente de revelación. En la comprensión el intérprete no es realmente sujeto, pues la comprensión se produce propiamente en cuanto acaecer de la propia tradición, lo cual exige que el intérprete deje de comportarse como sujeto, es decir, que adopte una actitud de dejar ser a la tradición. La tradición es constitutiva del modo de ser del intérprete y de su praxis interpretativa hasta tal punto que los prejuicios que ella transmite son hermenéuticamente productivos, en cuanto que son la condición de posibilidad de la propia comprensión: de este modo los actos de comprensión pueden ser entendidos como la mediación de la tradición consigo misma, a través de la praxis interpretativa del intérprete. En consecuencia resultan como tales no sólo filosóficamente aproblemáticos sino fundamentales para una teoría de la interpretación y de la comprensión como es la hermenéutica filosófica de Gadamer. Como hemos visto, no existe de principio en Gadamer la sospecha, que sí se da en el primer Heidegger, de que los prejuicios transmitidos por la tradición resulten distorsionantes de la experiencia y de la investigación hermenéutica misma 43 .

\footnotetext{
41 El concepto de tradición como legado de posibilidades que el Dasein se ve abocado a repetir tiene en todo caso una fuerte connotación conservadora, pues tal como aparece formulado en Ser y tiempo el Dasein no puede crear o alumbrar sus posibilidades de existencia, sólo puede elegirlas a partir de las que la tradición le ofrece como ya realizadas en el pasado.

42 Ver M. Heidegger, Identidad y diferencia, Barcelona, Anthropos, 1988.

43 Gadamer, Verdad y método, ed. cit., pp. 344 y ss.
} 
El acontecer de la tradición aparece en Gadamer caracterizado sistemáticamente en términos virtuosos: como hemos sostenido, en cuanto constitutivo del intérprete y como productivo de cara a la interpretación, pero además como lo que en realidad acontece en cada acto de comprensión y como lo que establece una continuidad esencial entre los diversos actos de comprensión a lo largo de la historia. A pesar de que Gadamer sostiene que la hermenéutica tiene como punto de partida una situación de extrañamiento respecto de la tradición (promovido, puede pensarse, por las condiciones de la vida moderna), lo cierto es que los actos de comprensión exitosos son aquellos que logran que acaezca sentido en el marco de la continuidad esencial, cabe decir, ontológica, que define a la tradición cultural occidental desde los antiguos griegos hasta nuestros días ${ }^{44}$. Gadamer acepta que determinados prejuicios pueden ser hechos reflexivos, pero para él todo ello posee un significado secundario en tanto que no concibe la interpretación como un acto subjetivo del intérprete, pues, como se ha visto, la comprensión constituye propiamente un acontecer de la propia tradición.

\section{5. ¿Una tradición de la crítica?}

Pero hay algo en lo que coinciden fundamentalmente las concepciones de la tradición del primer Heidegger y de Gadamer y es en su carácter sustantivo, homogéneo y englobante, que pierde de vista la posibilidad de la existencia de diferencias internas significativas en el seno de lo denominado, en singular, como la tradición. En Ser y tiempo el concepto propio o genuino de tradición remite a la tradición de la comunidad cultural nacional ${ }^{45}$ y las reflexiones de Gadamer toman claramente como referente a la tradición cultural occidental en cuanto tal46. En ambos casos se trata, pues, de la tradición, sin que se logre tematizar la existencia de una multiplicidad y un antagonismo en el seno de tal aparente unidad monolítica. Esto va a marcar las distancias de principio con el modo en que el concepto de tradición puede resultar significativo y lo ha sido de hecho para los autores del marxismo occidental y de la Teoría Crítica. Ya Gramsci sostuvo que "cada grupo social tiene una «tradición»"47. También Benjamin afirmó la contraposición entre lo que denominó tradición de los oprimidos y la de los opresores: si la primera está caracterizada por la continuidad (como es también el caso del concepto de tradición de Gadamer), que alimenta la idea de una transmisión de una identidad de sentido (y, como denuncia

\footnotetext{
44 Ibid., pp. 367 y 399.

45 Ver Heidegger, Ser y tiempo, ed. cit., \$74.

46 Gadamer, Verdad y método, ed. cit., p. 267.

47 A. Gramsci, Cuadernos de la cárcel, vol. 4, México, Era, 1986, p. 228.
} 
Benjamin, incluso de un desarrollo y de un progreso), la tradición de los oprimidos está marcada por la discontinuidad y la fragmentación 48 .

Esta tesis que defiende la existencia simultánea de una diversidad de tradiciones que conviven y se confrontan en el seno de una misma sociedad, diversidad que remite a una multiplicidad de posiciones sociales y no tanto a una diferencia religioso-cultural, en ascenso en las sociedades caracterizadas por la inmigración, es relevante porque permite de principio socavar la representación homogeneizadora $\mathrm{y}$ unitaria de la tradición al modo de una instancia que todo lo envuelve y todo lo media con su acaecer. Permite por tanto confrontarnos con una concepción ontológica y totalitaria de la tradición. Pero al mismo tiempo, permite deshacerse de la paradoja del primer Heidegger, consistente en que una y la misma tradición pueda aparecer como tradición inauténtica en el espacio público anónimo y como legado genuino de posibilidades de existencia para los individuos en el virtuoso estado de resolución. Con una visión adecuada de la diversidad existente en el ámbito de la tradición, puede constatarse que lo que impera irreflexiva y coactivamente en el espacio de lo público es una determinada tradición, la tradición hegemónica, dominante, pero que frente a ella resisten, reaccionan, son fagocitadas o se diluyen otras tradiciones, a menudo tradiciones contrapuestas. No me refiero aquí tanto, como apuntaba antes, a las tradiciones culturales y religiosas diversas, propias de las minorías étnico-religiosas generadas en las sociedades desde antiguo por las dinámicas de migración, colonización, etc., sino más propiamente a las tradiciones ético-políticas diversas en pugna dentro de la propia estructura social.

Esto es relevante para lo siguiente: puede sostenerse parafraseando a Benjamin que la crítica es un asunto de tradición ${ }^{49}$. Efectivamente, los parámetros normativos que sustentan la crítica en cada caso son trasmitidos por una determinada tradición. Los parámetros normativos que sostienen la crítica de un sujeto concreto han sido apropiados y asimilados por él en su proceso de socialización familiar, interpersonal, institucional y político, en un proceso que debe ser calificado de transmisión de una determinada tradición. Los parámetros normativos que sostienen la crítica proceden así de la tradición y cabe afirmar además que la socialización de un individuo, como capaz de criticar determinadas injusticias, debe ser considerada como un proceso de inserción en una tradición. En efecto, las diversas tradiciones ético-políticas en pugna incluyen un componente fundamental de pretensión de nor-

\footnotetext{
48 Ver W. Benjamin, Abhandlungen, Frankfurt a.M., Suhrkamp, 1991, vol. I.3, pp. 1223-1246. Gramsci, en su cuaderno de la cárcel titulado "Al margen de la historia. (Historia de los grupos sociales subalternos)" caracteriza también la historia de las clases subalternas como "«disgregada» y discontinua”, A. Gramsci, Cuadernos de la cárcel, México, vol. 6, México, Era, 2000, p. 182.

49 En su segundo ensayo sobre Baudelaire sostuvo Benjamin que "la experiencia, tanto en la vida colectiva como en la privada, es un asunto de la tradición", W. Benjamin, Poesía y capitalismo, Madrid, Taurus, 1993, p. 125.
} 
matividad. Los individuos son socializados en cada caso en un marco determinado de normatividad, pero tal proceso sólo alcanza adecuado cumplimiento cuando los sujetos llegan a ser capaces de dar cuenta con razones y argumentos de la validez de determinados parámetros normativos que han asimilado o bien de la falta de validez de parámetros que asimilaron en su proceso de socialización, pero que al cabo han perdido su poder de convicción. Este proceso puede ser concebido como un proceso de tornarse reflexiva la propia tradición, quizá no íntegra ni repentinamente, pero sí en un decurso en el que caben importantes rupturas con el marco normativo en el que se ha sido socializado.

Si los principios normativos heredados de la tradición forman parte de la situación hermenéutica de una determinada posición teórica, entonces la diversidad de situaciones hermenéuticas y con ello de perspectivas que conviven y se enfrentan en el marco social antagónico vigente tiene como sustento la existencia de una pluralidad de tradiciones que corresponden con la diversidad normativa realmente existente en las sociedades ya antes de la época moderna. Pero no sólo los parámetros normativos de una determinada situación hermenéutica son ubicables como parte de una tradición, también el diagnóstico de la problemática presente, el planteamiento de la cuestión que incita a la intervención teórica, a pesar de ser formulados por un sujeto o un equipo de investigadores particular, pueden ser concebidos como siendo parte de una tradición ético-política determinada.

De este modo, convergemos aquí con las ideas del primer Habermas, el cual defendió una sociología "crítica en el sentido altamente dialéctico de una conservación de su propia tradición crítica", a saber la tradición encarnada en la "ilustración humanista" 50 . Aquí el baremo de la crítica se definiría a partir del contraste entre el "recuerdo de lo que otrora se intentó con lo hoy diariamente a realizar y realmente alcanzado" 51. De este modo, hay que entender las tareas críticas de la sociología como tareas "auténticamente conservadoras, pues el motivo de la crítica lo extrae únicamente de una conservación de su propia tradición crítica" 52 . Por ello sostuvo Habermas en aquel momento que la sociología "alcanza la dimensión de la crítica por un camino hermenéutico: la dogmática de la situación vivida no se elimina mediante la formalización", sino que sólo se deja "sobrepasar desde el interior, por así decirlo, en el curso de una identificación con las tradiciones vigentes" 53 .

Estas reflexiones pretenden contrarrestar la representación de la actitud crítica como posicionada en una toma de partido no fundamentable racionalmente, una

\footnotetext{
50 J. Habermas, Teoría y praxis, Madrid, Tecnos, 1990, p. 286.

51 Ibid.

52 Ibid., p. 287.

53 Ibid., p. 286. En la nueva edición de Teoría y praxis de 1971 pudo afirmar Habermas que ya no mantenía esta posición, pues "una pragmática universal desarrollada nos permitirá indicar los títulos legales de la crítica que no pueden afianzarse contingentemente en las tradiciones históricas.” Ibid., p. 287, nota 25 .
} 
toma de partido consistente en un acto libre no argumentable. Efectivamente, esta es una representación abstracta de la toma de posición inherente a todo acto de crítica, pues abstrae el modo en que tal toma de posición tiene como condición previa el hecho de que el individuo están incardinado ya siempre en el seno de un determinado marco normativo, fruto de su proceso de socialización durante su biografía, es decir, de la integración, finalmente consciente y justificable mediante argumentos con pretensión de validez, en una determinada tradición en pugna con otras tradiciones en el mismo espacio social. Un componente fundamental por tanto de la historicidad y facticidad de la crítica social es su formar parte de la tradición o, mejor dicho, de las tradiciones de luchas a favor de la abolición de la opresión y la explotación.

Forma parte pues de la autorreflexión que se apropia de tal historicidad y facticidad de la crítica una vinculación explícita con una determinada tradición, en el modo de una inserción de la propia praxis crítica en la discontinuidad de los esfuerzos críticos del pasado. La praxis de la crítica es así una praxis saturada de memoria, es memoria en acto que, en su entrelazamiento con las luchas del pasado, pretende conmover los estrechos límites del presente y alumbrar una trascendencia posible para la acción política de los colectivos que sufren el estado de cosas vigente.

\section{Pluralismo y diálogo}

Lo expuesto hasta el momento nos conduce a la tesis de la existencia de una pluralidad de tradiciones coetáneas y, a menudo, en conflicto, en el interior de cada formación social. La distinción de Benjamin entre la tradición de los opresores y la de los oprimidos remite a esta situación. Pero no sólo en el seno de cada formación social, también a nivel global cabe explicitar una multiplicidad de tradiciones. Pero no sólo, de nuevo, entre los ámbitos de los socialmente dominantes y los dominados, sino en el seno de estos últimos. Efectivamente, puede sostenerse la existencia de una pluralidad de tradiciones de lucha por la dignidad, la justicia y la igualdad, etc., tanto en el seno de cada sociedad concreta, como a nivel global. Las tradiciones de la organización obrera, del movimiento feminista, de la lucha por los derechos de minorías étnicas, sexuales, religiosas, en los países industriales y en los antiguos países colonizados y en los ubicados más allá del mundo desarrollado occidental, sin olvidar las diversas tradiciones de luchas anticoloniales: todas ellas constituyen tradiciones de hecho diferentes, que comparten determinados principios normativos pero no otros y discrepan a menudo en cómo interpretar los parámetros normativos que en principio parecen compartir.

Este pluralismo de tradiciones, también en el ámbito de los que se enfrentan a la compleja trama de múltiples relaciones de opresión y explotación existentes, no 
implica la inconmensurabilidad e incomunicabilidad entre tales tradiciones. La discusión, la confrontación de puntos de vista, la influencia y la ósmosis entre tradiciones existe y ha existido a lo largo de la historia. La cuestión es si tales procesos de discusión pueden dar lugar a un diálogo orientado al entendimiento. El concepto de diálogo fue ya central en la hermenéutica de Gadamer ${ }^{54}$, pero resulta ciertamente paradójico el significado que el diálogo recibe en su planteamiento en cuanto diálogo efectuado en el seno de la tradición compartida por los interlocutores. Pues, según este punto de vista, es el formar parte de la misma tradición lo que posibilitaría el diálogo, ya que en esencia, piensa Gadamer, todo diálogo entre sujetos en el presente es un diálogo con la propia tradición, con la tradición compartida, común. Esto hace del diálogo en Gadamer no una interacción orientada a obtener un consenso, sino un intercambio hecho posible por un consenso en el que los intérpretes ya siempre están: el consenso definido por la tradición compartida.

Esta concepción del diálogo fue duramente cuestionada por Habermas en los años sesenta 55 . Habermas considera que el consenso fundado en la tradición, que según Gadamer no requiere de una ilustración racional, en tanto que tal pretensión es en definitiva quimérica, no es sin más aproblemático. Sostiene la posibilidad, no percibida por Gadamer, de que los consensos vigentes, sustentados por la tradición, sean efectivamente pseudo-consensos, es decir, consensos obtenidos no a través de la interacción libre de sujetos que participan con autonomía en un diálogo real, sino generados mediante coacciones encubiertas, como son las coacciones procedentes, pensaba Habermas entonces, del ámbito político y de la organización de la economía. Si los consensos vigentes sustentados en la tradición tal como son conseguidos en el marco de las relaciones de dominación y coacción socio-económicas vigentes pueden ser efectivamente pseudo-consensos, entonces no pueden fundar diálogo alguno. Se trata entonces, a la inversa, de establecer las condiciones sociales e institucionales que hagan posible la realización de diálogos reales, capaces de generar consensos válidos y vinculantes sobre las cuestiones y problemas relevantes desde un punto de vista práctico a nivel colectivo.

Coincido fundamentalmente con la crítica de Habermas a Gadamer, pero me pregunto si su noción de un diálogo orientado al entendimiento puede resultar fructífera en el ámbito de la relación entre las diversas tradiciones que se oponen en el terreno social. Tengo serias dudas de que un tal diálogo pueda realizarse efectivamente entre tradiciones que articulan intereses sociales antagónicos: entre tales tradiciones cabe naturalmente la discusión, la contraposición de argumentos, el reproche y la denuncia, pero no se percibe como factible la consecución de un consenso entre tales tradiciones, ni que tal improbable consenso pueda conseguir consecuen-

\footnotetext{
54 Ver Gadamer, Verdad y método I, ed. cit., pp. 446 y ss.

55 Ver, sobre todo, Habermas, La lógica de las ciencias sociales, Madrid, Tecnos, 1988, pp. $257-9$.
} 
cias prácticas. El propio Habermas reconoce que el consenso sólo es posible sobre la base de un interés común, en caso de intereses contrapuestos sólo cabe negociar ${ }^{56}$. El concepto de un diálogo orientado al entendimiento tiene en cambio sentido en el marco de la interacción de las tradiciones que, cada una a su modo, se enfrentan a un marco de opresiones y explotaciones diversas devenido global. Es aquí donde considero factible la confrontación orientada a la consecución de una posición en la que converjan las diversas perspectivas en juego, una posición que si bien no supondría un consenso sí permitiría hablar de un entendimiento con consecuencias productivas de cara a la coordinación de una praxis política común. Sería un diálogo de este tipo, un diálogo que a todas luces está en marcha, en el que se da a la vez un proceso de universalización a partir de las propias perspectivas y de afrontamiento de los problemas desde el grado de desarrollo social definido a partir de las capacidades incorporadas subjetivamente y plasmadas en el cuerpo social, lo que debería ser calificado en sentido propio como racional.

\section{Bibliografía}

Benjamin, W.: Abhandlungen, Frankfurt a.M., Suhrkamp, 1991.

Benjamin, W.: Poesía y capitalismo, Madrid, Taurus, 1993.

CANo, G: Nietzsche y la crítica de la modernidad, Madrid, Biblioteca Nueva, 2001.

Foucault, M.: La verdad y las formas jurídicas, Barcelona, Gedisa, 1992.

Gadamer, H.-G.: Verdad y método I, Salamanca, Sígueme, 1991.

GADAmer, H.-G.: Verdad y método II, Salamanca, Sígueme, 2002.

Gramsci, A.: Cuadernos de la cárcel, México, Era, 1986, 6 vols.

HABERMAs, J.: Teoría y praxis, Madrid, Tecnos, 1990.

Habermas, J.: La lógica de las ciencias sociales, Madrid, Tecnos, 1990.

Habermas, J.: Ciencia y técnica como "ideología”, Madrid, Tecnos, 1984.

Habermas, J.: Conocimiento e interés, Madrid, Taurus, 1989.

Habermas, J.: Conciencia moral y acción comunicativa, Barcelona, Península, 1996.

HeIDEgGer, M: La idea de la filosofia y el problema de la concepción del mundo, Barcelona, Herder, 2005.

HeIDEgGER, M: Hitos, Madrid, Alianza, 2000.

HEIDEGGER, M: Interpretaciones fenomenológicas sobre Aristóteles. Indicación de la situación hermenéutica, Madrid, Trotta, 2002.

HEIDEGGER, M: Introducción a la investigación fenomenológica, Madrid, Síntesis, 2008.

56 Ver J. Habermas, Conciencia moral y acción comunicativa, Barcelona, Península, 1996, pp. 93-4. 
Heidegger, M: Ontología. Hermenéutica de la facticidad, Madrid, Alianza, 1999. HeIdegGer, M: El concepto de tiempo (Tratado de 1924), Barcelona, Herder, 2008. Heidegger, M: Ser y tiempo, Santiago de Chile, Editorial Universitaria, 1998. HeIDEgGer, M: Identidad y diferencia, Barcelona, Anthropos, 1988.

HorkHeImer, M.: Teoría tradicional y teoría crítica, Barcelona, Paidós, 2000.

LuKÁCS, G.: Historia y consciencia de clase, México, Grijalbo, 1969.

MARCUSE, H.: La agresividad en la sociedad industrial avanzada, Madrid, Alianza, 1984.

Nietzsche, F.: Sämtliche Werke. Kritische Studienausgabe, Berlín/Nueva York, Walter de Gruyter/Dtv, 1988.

NietzSChe, F.: Sobre la utilidad y el perjuicio de la historia para la vida, Madrid, Biblioteca Nueva, 1999.

Nietzsche, F.: Humano, demasiado humano, Madrid, Akal, 1996, 2 vols.

NiETZSCHE, F.: Aurora, Barcelona, Alba Editorial, 1999.

NiETZSCHE, F.: La genealogía de la moral, Madrid, Alianza, 1973.

NieTZSChe, F.: Ecce homo, Madrid, Alianza, 1971.

RodRíGUEZ, R.: La transformación hermenéutica de la fenomenología, Madrid, Tecnos, 1997.

RodríGUEz, R.: Del sujeto y la verdad, Madrid, Síntesis, 2004.

RodRíGuez, R.: Hermenéutica y subjetividad, Madrid, Trotta, $2010^{2}$.

Romero, J.M.: El caos y las formas. Experiencia, conocimiento y verdad en F. Nietzsche, Granada, Comares, 2001.

ROMERo, J.M.: "Los frágiles cimientos del presente. La genealogía nietzschena y la verdad de la historia", en Estudios Nietzsche, n 3, 2003, pp. 141-161.

Romero, J.M.: Crítica e historicidad, Barcelona, Herder, 2010.

Romero, J.M.: "La problemática de la historicidad en el primer H. Marcuse", en Pensamiento, Madrid, 2013, vol. 69, $\mathrm{n}^{\mathrm{o}}$ 259, pp. 331-350..

Romero, J.M. (ed.): H. Marcuse y los orígenes de la teoría crítica, Madrid, Plaza y Valdés, 2010.

José Manuel Romero Cuevas

Universidad de Alcalá de Henares

josemanuel.romero@uah.es 